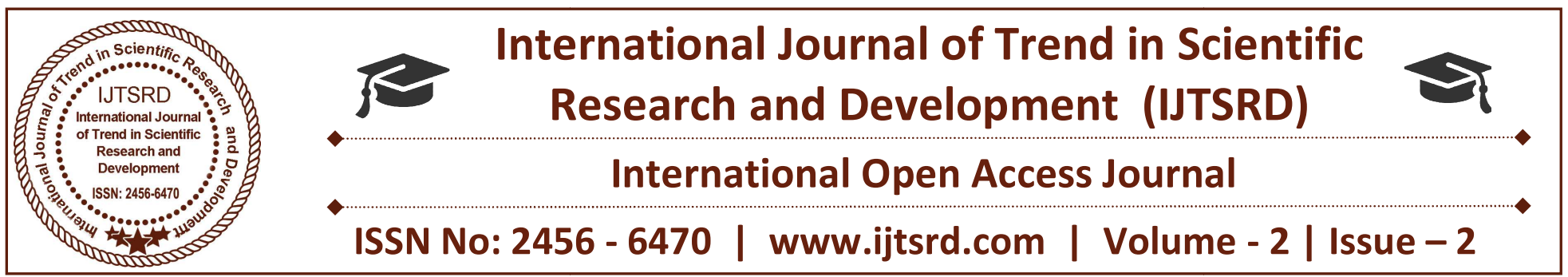

\title{
Hematological qualities induced by Methanolic Leaf Extract of Allium ampeloprasum in white mice
}

\author{
Azhar Shya Y. Albusasy \\ Department of Ecology, Faculty of Science, University of Kufa, \\ Kufa, Najaf Governorate, Iraq
}

\section{ABSTRACT}

Blood disorder has become a common problem for many people. Some medicinal plants are believed to promote positive health and maintain organic resistance against infection. The use of readily available medicinal plants, which can be said to be effective, will provide a better and affordable alternative to promoting and strengthening health. Evaluation of blood parameters can be used to determine the extent of the harmful effect of foreign compounds including plant extracts on blood components of white mice. Various chemical constituents of Allium ampeloprasum are believed to possess therapeutic effects on hematological parameters. However, these results have not been subject to systematic studies to substantiate the therapeutic claims made about clinical the benefit. This study designed to investigate Allium Hematological Allium ampeloprasum (Wild Leek) in white mice. This study was treated with leaf extracts at the concentration of $50 \mathrm{mg} / \mathrm{kg}$ and $100 \mathrm{mg} / \mathrm{kg}$ orally once per 2 days for 14 days. Blood parameters were determined using standard protocols of untested blood samples, and standard procedures were used to evaluate different types of phytochemical tests. The leaf extract of Allium ampeloprasum (Wild Leek) induced changes in erythrocytes, and detailed parameter profiles, total and white blood cell (WBC counts, platelets and their related parameters in white mice at the two tested dose levels of $50 \mathrm{mg} / \mathrm{kg}$ bw and $100 \mathrm{mg} / \mathrm{kg}$ bw. Further, the phytochemical screening results showed that the leaf extract of Allium ampeloprasum has phytochemicals associated with the erythropoietin promoting activity, immune stimulatory activities, and thrombopoietin stimulation.

Keywords: Hematological disorders; Allium ampeloprasum; Leaves extract; Erythropoietin promoting activity; Immuno stimulatory actions; Thrombopoietin stimulation

\section{Introduction}

The essential body fluid is blood, which accounts for $7 \%$ of body weight with a density of $1060 \mathrm{~kg} / \mathrm{m}^{3}$ and is composed of plasma and several kinds of cells which include erythrocytes, leucocytes and thrombocytes (Austin and Perkins, 2006). There arethree functions of Erythrocyte; to distribute $\mathrm{O}_{2}$ from the lungs, remove $\mathrm{CO}_{2}$ from the tissues back to the lungs, and ensure that the acidic and fundamental values of the body are healthy (Jagger et al.,2001).

Leucocytes (WBC) are the principal cells in the immune system that provide either adaptive or innate adaptive immunity. They are five different types. Neutrophils, monocytes, lymphocytes, eosinophils, and crusts. Leukocytes also classified into lymphocytes, granulocytes, monocytes, and natural killer cells (Mosmann and Coffman, 1989). Platelets have the essential function (pathophysiology) including ascites and thrombosis, thrombosis, vasoconstriction and repair, atherosclerosis, host defense and tumor growth (malignant tumor) (Paul, 2005).Treatment of anemia with ErythropoiesisStimulating Agents (ESA) effectively corrects the condition in patients with chronic kidney disease. 
Erythropoietin administration is recommended to improve hemoglobin in patients receiving solid organ (Tan-Shalaby and Tempero, 1995) . Neutrophils occur in cases of low white blood cell (WBC) production, increased use, and destruction, or both. In cases where causative factors such as drug status and folic acid deficiency can identify, treatment should be developed without delay (Bodeyet al.,1882). Thrombocytopenia means a reduction in the platelet count below the standard lower limit, which usually defined as $150 \times 109 / \mathrm{L}$ (Izak and Bussel, 2014). This can cause reduced platelet production, decreased plaque survival, and reduced platelet counts resulting from an inadequate blood transfusion (Bradbury and Murray, 2013). In case of severe thrombocytopenia or evidence of hemorrhage, a patient should receive immediate attention by undertaking platelet transfusion (Konkle, 2011).Most traditional methods of managing anemia, neutrophils and thrombocytopenia may be costly, have unwanted side effects, are painful to patients or are not easily accessible. All of these limitations involved in the use of traditional methods of managing blood disorders require the need to seek safer and more efficient alternative ways of the deficiencies above to contain and control these hematological disorders. It acknowledged worldwide that traditional medicine could be explored and exploited to be used along-side synthetic pharmaceutical products for enhanced health management (Imaga, 2010). Certain medicinal plants are believed to promote positive health and maintain organic resistance against infection by re-establishing body equilibrium and conditioning the body tissues (Sumitet al.,2014).

(Allium ampeloprasum L.) Is one of the widely used and is considered as a medicinal plant (1). It belongs to the lily family (Liliaceae), is dioecious and perennial, with band-shaped, relatively broad leaves with long sheaths. Components in leek may cause intestinal cancer reduction and blood cholesterol reduction. Different enzymes such as maltase, doctrines and invertase are available in leaves, as well as significant amounts of iron and vitamin $\mathrm{C}$. Vitamin B1 and B2. Also, leek contains manganese, calcium, phosphorus, sodium, potassium, vitamin A, and B6. Where its fungicidal, antiseptic, tonic and parasiticidal properties have proved of benefit. It has anticancer activity. Especially the blood system and the heart.

Therefore, this study aimed at evaluating the hematological effects of Methanolic leaf extract
(MLE) of Allium ampeloprasum (Wild Leek) on white mice as an initial step towards developing a more efficient agent derived from plants to manage blood disorders and promote health.

\section{Materials and Methods}

\section{Collection and preparation of sample materials}

Fresh leaves of Allium ampeloprasum collected from Farms in the Kufa city near Euphrates river in AlNajaf Alshraf province / Iraq. The information gathered included vernacular names, plant parts used and the ailment treated. The samples were correctly sorted out and transported in polythene bags to Kufa University, Biology and chemistry laboratories for drying and crushing. The identity of each of the plants authenticated by a taxonomist in the Department of biology, Kufa University. The fresh leaves of Allium ampeloprasum (Wild Leek) were cleaned with tap water and dried under shade then pulverized to the powder using an electrical blender.

\section{Extraction}

$500 \mathrm{mg}$ of the leaf weighed and soaked of $1 \mathrm{~L}$ of methanol in a conical flask. The vial containing the leaves shaken, and the asphalt was left to stand for 48 hours. At room temperature. The mixture filtered using filter papers (Whatman No.1) and the filtrate Rotaevaporated to dryness at $65^{\circ} \mathrm{C}$ to recover the extract. The concentrate stored at $4{ }^{\circ} \mathrm{C}$ before use in bioassay studies.

\section{Experimental animals and design}

Three to four-week-old healthy male albino mice weighing an average of $20 \mathrm{~g}$ used in this study. Ethical guidelines and procedures for handling animals followed. The animal randomly divided into two groups (Group A and B) of 5 mice each. Animals in Group A and B were orally administered with 50 $\mathrm{mg} / \mathrm{kg}$ body white and $100 \mathrm{mg} / \mathrm{kg}$ body white of methanolic extract respectively at intervals of two days for 14 days. The extract was administered using intragastric gavage technique. Blood from both groups of mice taken before the first oral administration. It repeated on seven days, during this period, mice were allowed free access to mice pellet.

\section{Preparation of extracts doses for administration}

The dose level of $50 \mathrm{mg} / \mathrm{kg}$ body white prepared using $0.04 \mathrm{~g}$ of the extract in $4.1 \mathrm{ml}$ of $30 \%$ 
dimethylsulfoxide and topping up to $10 \mathrm{ml}$ with water. While the dose level of $100 \mathrm{mg} / \mathrm{kg}$ body white prepared by dissolving $0.084 \mathrm{~g}$ at $4.2 \mathrm{ml}$. Dimethylsulfoxide and topping up to $10 \mathrm{ml}$ of water.

Blood samples collected, they are on the 7thand 14th days from the tails of mice for the determination of hematological parameters. The tails first sterilized by swabbing with $70 \%$ ethanol and then the tip of the tails snipped with sterile scissors. Blood of approximately $0.2 \mathrm{ml}$ drawn into bottles containing anticoagulant (EDTA) shaken and taken for hematological parameter assessment. (American Society of Clinical Oncology ,1994)

\section{Determination of hematological parameters}

Hematological parameters and indices were determined from unclotted blood samples using standard protocols (Jain, 1986). Erythrocytes, hemoglobin concentration, hematocrit, mean corpuscular volume, mean corpuscular hemoglobin, mean corpuscular hemoglobin concentration, red cell distribution width and platelets, plateletcrit, mean platelet volume and platelet distribution width, were determined using the Coulter Counter System (Beckman Coulter ${ }^{\circledR}$, Thermo Fisher, UK). Air-dried thin blood films stained with Giemsa stain were examined microscopically using magnification x 200 and $x 400$ for differential white blood cell counts.(

\section{Qualitative phytochemical screening}

The crude extracts obtained were subjected to qualitative phytochemical screening to identify presence or absence of selected chemical constituents using methods of analysis as described by (Harbone, 1998) and (Kotake, 2000). Secondary metabolites tested.

\section{Data management and Analysis}

Experimental data on different hematological parameters obtained from all the animals. It was recorded and tabulated on a broadsheet using Excel program. The results expressed as mean \pm Standard Error of Mean (SEM) for analysis. Statistical significance of the difference between the two groups was analyzed using one-way analysis of variance (ANOVA) followed by Tukey's tests to separate the means and obtain the specific significant differences among the different groups. The values of $\mathrm{P} \leq 0.01$ were considered to be substantial.

\section{Results}

(MLE) of Allium ampeloprasum (Wild Leek) induced changes in (RBC) and related parameter profiles in white mice (Table 1). After seven days of oral intake of the extracts at $50 \mathrm{mg} / \mathrm{kg}$ body weight and 100 $\mathrm{mg} / \mathrm{kg}$ body weight, there was a significant increase in erythrocyte counts and hematocrit count $(p<0.01$; table 1). The levels of the two doses did not have any significant effects on $\mathrm{Hb}, \mathrm{MCV}, \mathrm{MCH}, \mathrm{MCHC}$ and RDW profiles in white mice $(\mathrm{P}>0.01$; Table 1$)$.

Table 1: Effects of (MLE) of Allium ampeloprasum (Wild Leek) on Erythrocytes and related parameter profiles in white mice

\begin{tabular}{|c|c|c|c|c|c|c|}
\hline \multirow{2}{*}{ Parameters } & \multicolumn{3}{|c|}{$\mathbf{5 0 m g / k g b w}$} & \multicolumn{3}{c|}{ 100mg/kgbw } \\
\cline { 2 - 7 } & Day 0 & Day 7 & Day 14 & Day 0 & Day 7 & Day 14 \\
\hline Erythrocytes & $2.98 \pm 0.08$ & $5.57 \pm 0.10$ & $5.83 \pm 0.09$ & $3.35 \pm 0.15$ & $5.30 \pm 0.08$ & $5.72 \pm 0.13$ \\
\hline Hb & $6.74 \pm 0.44$ & $7.91 \pm 0.6$ & $8.12 \pm 0.90$ & $6.11 \pm 0.12$ & $7.21 \pm 0.25$ & $8.65 \pm 0.5$ \\
\hline Hematocrit & $16.74 \pm 0.86$ & $26.05 \pm 1.18$ & $30.27 \pm 0.43$ & $15.75 \pm 0.69$ & $23.81 \pm 1.5$ & $26.44 \pm 0.86$ \\
\hline MCV & $51.82 \pm 1.63$ & $49.28 \pm 1.46$ & $54.77 \pm 0.54$ & $53.20 \pm 0.00$ & $51.82 \pm 3.23$ & $55.43 \pm 2.61$ \\
\hline MCH & $13.96 \pm 0.47$ & $14.82 \pm 0.40$ & $15.08 \pm 0.4$ & $13.76 \pm 0.50$ & $14.62 \pm 0.34$ & $15.13 \pm 0.23$ \\
\hline MCHC & $27.08 \pm 1.26$ & $30.10 \pm 0.51$ & $28.85 \pm 0.59$ & $26.86 \pm 86$ & $28.50 \pm 1.19$ & $28.18 \pm 0.98$ \\
\hline RDW & $15.64 \pm 0.56$ & $14.92 \pm 0.39$ & $16.76 \pm 0.47$ & $16.22 \pm 0.65$ & $15.54 \pm 0.65$ & $15.54 \pm 0.65$ \\
\hline
\end{tabular}

All values expressed as mean \pm SEM for five animals per group. Values for each parameter compared to each dose using ANOVA and Tukey's post hoc test. 
Effects of (MLE) of Allium ampeloprasum (Wild Leek) in total WBC and differential WBC counts in white mice

(MLE)of Allium ampeloprasum (Wild Leek) induced changes in total differential WBC counts in white mice (Table 2). The dose level of $50 \mathrm{mg} / \mathrm{kg}$ body white did not have any significant effect on overall WBC, monocytes and eosinophils counts $(\mathrm{p}>0.01$;
Table 2), but it caused a significant increase in neutrophils, lymphocytes and basophils numbers $(\mathrm{p}<0.01 ;$ Table 2$)$. The dose level of $100 \mathrm{mg} / \mathrm{kg}$ body white caused a considerable increase in total WBC, neutrophils, and basophils counts $(\mathrm{p}<0.01$; Table 2$)$ but had no significant effect on monocytes and eosinophils counts ( $>0.01$; Table 2$)$.

Table 2: Effects of (MLE) of Allium ampeloprasum (Wild Leek) on (WBC) and their differentials parameter profiles in white mice.

\begin{tabular}{|l|l|l|l|l|l|l|}
\multirow{2}{*}{ Parameters } & \multicolumn{5}{l}{$50 \mathrm{mg} / \mathrm{kgbw}$} & \multicolumn{7}{l}{$100 \mathrm{mg} / \mathrm{kgbw}$} \\
\cline { 2 - 7 } & Day0 & Day 7 & Day 14 & Day 0 & Day 7 & Day 14 \\
\hline WBC & $5.22 \pm 0.15$ & $6.72 \pm 0.56$ & $7.20 \pm 0.37$ & $5.56 \pm 0.24$ & $7.48 \pm 0.12$ & $7.92 \pm 0.12$ \\
\hline Neutrophils & $0.78 \pm 0.04$ & $1.34 \pm 0.06$ & $1.92 \pm 0.06$ & $0.76 \pm 0.16$ & $1.42 \pm 0.11$ & $1.86 \pm 0.11$ \\
\hline Lymphocytes & $3.22 \pm 0.09$ & $3.86 \pm 0.10$ & $4.16 \pm 0.10$ & $4.04 \pm 0.09$ & $3.98 \pm 0.04$ & $4.12 \pm 0.06$ \\
\hline Monocytes & $0.00 \pm 0.0$ & $0.00 \pm 0.00$ & $0.06 \pm 0.0$ & $0.00 \pm 0.00$ & $010 \pm 0.08$ & $0.24 \pm 0.09$ \\
\hline Eosinophils & $0.022 \pm 0.05$ & $0.02 \pm 0.02$ & $0.40 \pm 0.13$ & $0.12 \pm 0.06$ & $0.01 \pm 0.03$ & $0.22 \pm 0.07$ \\
\hline Basophils & $0.14 \pm 0.05$ & $0.70 \pm 0.13$ & $1.14 \pm 0.02$ & $0.20 \pm 0.03$ & $0.60 \pm 0.11$ & $1.12 \pm 0.08$ \\
\hline
\end{tabular}

Effects of (MLE) of Allium ampeloprasum (Wild Leek) in platelets and their related parameter profiles in white mice.

The (MLE) of Allium ampeloprasum (Wild Leek) also induced changes in platelets and their related parameter profiles in white mice (Table 3 ). The dose level of $50 \mathrm{mg} / \mathrm{kg}$ body white caused a significant increase in platelets and MPV levels after seven days of administration ( $\mathrm{p}<0.01$; Table 3 ) but did not have a considerable effect in plateletcrit and PDW ( $>0.01$; Table 3 ). The dose level of $100 \mathrm{mg} / \mathrm{kg}$ body white caused a significant increase in platelet and plateletcrit after fourteen days (Table 3). It also created a significant rise in MPV after seven and fourteen days of oral intake ( $\mathrm{p}<0.01$; Table 3$)$ but did not have any significant effect on PDW $(\mathrm{p}>0.01$; Table 3$)$.

Table 3: Effects of (MLE) of Allium ampeloprasum (Wild Leek).

\begin{tabular}{|c|c|c|c|c|c|c|}
\hline \multirow{2}{*}{ Parameters } & \multicolumn{3}{|c}{$50 \mathrm{mg} / \mathrm{kgbw}$} & \multicolumn{3}{c|}{$100 \mathrm{mg} / \mathrm{kgbw}$} \\
\cline { 2 - 8 } & Day 0 & Day 7 & Day 14 & Day 0 & Day 7 & Day 14 \\
\hline Platelets & $206.60 \pm 4.25$ & $368.40 \pm 7.81$ & $423.80 \pm 19.4$ & $203.6 \pm 13.9$ & $257.80 \pm 9.98$ & $382.00 \pm 4.83$ \\
\hline Plateletcrit & $0.04 \pm 0.00$ & $0.08 \pm 0.01$ & $0.31 \pm 0.20$ & $0.04 \pm 0.0$ & $0.06 \pm 0.01$ & $0.14 \pm 0.01$ \\
\hline MPV & $1.72 \pm 0.12$ & $2.06 \pm 0.14$ & $2.64 \pm 0.12$ & $1.80 \pm 0.05$ & $2.64 \pm 0.13$ & $3.36 \pm 0.15$ \\
\hline PDW & $14.86 \pm 0.37$ & $14.68 \pm 0.18$ & $15.18 \pm 0.40$ & $15.08 \pm 0.39$ & $14.60 \pm 0.56$ & $15.75 \pm 0.35$ \\
\hline
\end{tabular}


All values expressed as mean $\pm \mathrm{SEM}$ for five animals per group.

\section{Phytochemical screening}

Qualitative phytochemical screening of the (MLE) of Allium ampeloprasum (Wild Leek) indicated the presence of alkaloids, flavonoids, saponins, phenolics and tannins (Table 4).

Table 4: Qualitative phytochemical screening of (MLE) of Allium ampeloprasum.

Phytochemicals

\begin{tabular}{|c|c|}
\hline Alkaloids & + \\
\hline Flavonoids & + \\
\hline Steroids & - \\
\hline Saponins & + \\
\hline Cardiac glycosides & - \\
\hline Phenolics & + \\
\hline Terpenoids & - \\
\hline Tannins & + \\
\hline pentanol & + \\
\hline 5,2-methyl furan & + \\
\hline octa decan & + \\
\hline dipropyl disulphide & + \\
\hline $\begin{array}{c}\text { methyl alil sulphide } \\
\text { ketra hydro 5-2 dimethyl tiophone }\end{array}$ & + \\
\hline kamphore & + \\
\hline maltase, doctrinase and invertase & + \\
\hline
\end{tabular}

$(+)$ the sign denotes present phytochemicals, absent phytochemicals are indicated by (-) s.ymbol

\section{Discussion}

The present study showed that (MLE)of Allium ampeloprasum (Wild Leek) varying degrees of hematological at the dose level of $50 \mathrm{mg} / \mathrm{kg} \mathrm{bw}$ and $100 \mathrm{mg} / \mathrm{kgbw}$.

The significant increase in hematocrit counts and erythrocytes after oral intake of (MLE) of Allium ampeloprasum indicates that extracts stimulated the formation of erythropoietin, a glycoprotein that stimulates bone marrow stem cells to produce red blood cells (Ohlsson, 2009). Erythropoietin affects the blood's ability to carry oxygen and the amount of oxygen delivered to tissues because red blood cells and hemoglobin are essential for the transport of respiratory gases (Oyedeji and Bolarinwa, 2013). The extracts may contain compounds and phytochemicals that stimulate the formation or secretion of erythropoietin in the stem cells of white mice. Therefore, the (MLE) of Allium ampeloprasum (Wild Leek) can be used to restore lost blood during excessive bleeding.
The presence of antioxidant phytochemicals like flavonoids and tannins in the (MLE) of (Wild Leek) may be responsible for the hemopoietic stimulating effects As (Chris et al.,2008) observed. The previous research has shown that oral and oral treatment of antioxidant supplements in plant extracts significantly increased the blood-producing cells in animals exposed to lethal dose of radiation (Chris et al.,2008). Flavonoids, tannins, and terpenes were found to protect the erythrocyte from oxidation damage (Grassmann, 2005). Furthermore, (Chaharet al.,2011) and (Ren et al.,2003) are reported that Flavonoids have different benefits to human health due to their antioxidant activities and free scavenging roots as well as anti-inflammatory, antiviral, and anti-cancer properties. As (Dahanukaret al.,2000) laments, immunosuppression through stimulation or suppression may help maintain a disease-free condition. Agents that activate host defense mechanisms in a weak immune response can provide supportive therapy for conventional chemotherapy. The significant increase in the test animals shows that MLE of Allium ampeloprasum may have immuneboosting properties similar to garlic Allumsativum 
(Linn) (Iranloye, 2002) and seed extracts of Citrus paradiseMacfad by (Adeneye, 2008). It has reported that granulocyte-macrophage colony stimulating factor, macrophage colony stimulating factor, interleukins IL -2 IL-4 and IL-5 regulate the proliferation, differentiation, and maturation of committed stem cells responsible for the production of (WBC) (Ganong, 2001). Since the (MLE)of Allium ampeloprasum caused increases in (WBC) counts.

This is similar to research have shown the capacity of medicinal plants to induce immunostimulatory effects in animals. (Dahanukar and Thatte, 1994) demonstrated that Asparagus racemosus, Tinosporacordifolia (Willd) and Withaniasomnifera (Linn) protected animals against infections in healthy and immunosuppressed states induced by hemisplenectomy or surgery. Furthermore, it has shown these plants also produced leucocytosis and prevented the leucopenia caused by cyclophosphamide. The mode of action found to be activation of the polymorphonuclear and monocyte-macrophage systems (Dahanukar and Thatte, 1994). It increased the peritoneal macrophages and induced an elevation of delayed hypersensitivity reaction in mice.

These stimulant effects could associate with the adjuvant activity of some phytochemicals found in the extract. Saponins, alkaloids, tannins, phenolic compounds, and flavonoids have been reported as immunostimulants (Dashputre and Naikwade, 2010). MLE of Allium ampeloprasum elevated neutrophil counts in white mice suggests that the extracts could help to increase the immunity against microbial infections (Gautamet al., 2004).

The significant increase in platelets and their related parameter profiles after oral administration of (MLE) of Allium ampeloprasum (Wild Leek) suggests that the extracts contain compounds and phytochemicals that may have stimulated thrombopoietic process in white mice.

The significant increase in platelet count of extracts of Allium ampeloprasum (Wild Leek) indicates the extracts have the potential to be developed as plantbased therapeutic agents for thrombocytopenia. This agrees with (Subenthiranet al.,2013), who reported that leaf juice of Carica papaya (Linn) consumed during dengue infection had the potential to induce platelet production. or may have been attributed to the presence of tannins which have been shown to confer anti-hemorrhagic properties in mice. This is consistent with the findings of (Asquith and Butler, 1986) that the sap of Musa paradisiacal is used to treat fresh wounds, bites and insect bites.

\section{Conclusions}

The current study showed that oral administration of the methanol leaf extract from the Allium ampeloprasum in the white mice resulted in a significant improvement in the parameters of the (RBC) parameter. This may suggest that plants possess activity promoting erythropoietin and phytochemicals that slow down the natural process of oxidative breakdown of (RBC) and thus have a promising role in treatment and prevention of anemia. That the significant increase in total (WBC) and differential (WBC) counts in white mice after oral administration of the extract shows that the plants may promote the immune stimulatory activities hence can be pursued for their clinical relevance in the management of immunity-dependent disorders. The results showed the significant increase in platelet and their related parameters in white mice after treatments of the extract that mean the extracts have a potential rule to stimulate thrombopoietin production, and This leads to the possibility of using the extract to manage the hemostatic capacity of blood .Furthermore, classes of phytochemicals in (MLE)of Allium ampeloprasum have previously been reported to have antioxidant activity .

The present study, therefore, scientifically confirms and supports the traditional use of leaves of Allium ampeloprasum (Wild Leek) in enhancing hematological parameters and improving health.

\section{Acknowledgement}

The author acknowledges the financial support of the University of Kufa, Iraq. The author is grateful to Dr. Basim A. Almayahi, Department of Ecology, College of Science, University of Kufa (basimnajaf@yahoo.com) for assisting me throughout conducting the present research.

\section{REFERENCES}

1. Adeneye AA (2008) Hematopoietic effect of methanol seed extract of Citrus paradise Mac fad (grapefruit) in Westar rats. Biomedical Research 19: 23-26.

2. American Society of Clinical Oncology (1994) Recommendations for the use of hematopoietic colony-stimulating factors: evidence-based, 
clinical practice guidelines. Journal of Clinical 15. Imaga NOA (2010) The use of phytomedicines as Oncology12: 2471-2508.

3. Asquith TN, LG Butler (1986) Interaction of condensed Tannins with selected proteins. Phytochemistry 25: 1591-1593

4. Austin CC, Perkins SL (2006) Parasites in a biodiversity hotspot: a survey of hematozoa and a molecular phylogenetic analysis of Plasmodium in New Guinea skinks. Journal of Parasitology 92: 770-777.

5. Bodey GP, Bolivar R, Feinstein V (1882) Infectious complications in leukemia patients. Seminar in Hematology 19: 193-220.

6. Bradbury C, Murray J (2013) Investigating an 19 incidental finding of thrombocytopenia. British Medical Journal 346:f11

7. Chahar MN, Sharma MP, Dobhal YC (2011) Flavonoids: a versatile source of anticancer drugs.Pharmacognosy Review 5: 1-12.

8. Chris W, jennies, styrene, Manunya N, James D (2008)

Dietary anti-oxidant protecthemoautopoietic cell and improve animal survival after total body irradiation. Journal of Radials Research 169: 384 =-366.

9. Dahanukar SA, Kulkarni RA, Rege NN (2000) Pharmacology of medicinal plants and natural products. Indian Journal of Pharmacology 32: 81118.

10. Dashputre NL, Naikwade NS (2010) Immunomodulatory Activity of Abutilon Indicum (link) in Albino Mice. International Journal of Pharmaceutical Sciences and Research (IJPSR) 1: 178-184.

11. Ganong WF (2001) Review of Medical Physiology. (20th Edn), Lange Medical Books, McGraw Hill Companies Inc., New York.

12. Gautam M, Diwanay S, Gairola S, Shinde Y, Patki $\mathrm{P}$, et al. (2004) Immunoadjubent potential of Asparagus racemosus aqueous extract in the experimental system. Journal of 27. Ethnopharmacology 91: 251-255

13. Grassmann J (2005) Terpenoids as plant antioxidants. Vitamin and Hormones 72: 505-535

14. Harborne JB (1998) Phytochemical Methods: A Guide to Modern Techniques of Plant Analysis. Chapman \& Hal Publishers 3: 60-66.

28. Tan-Shalaby J, Tempero M (1995) Malignancies after liver transplantation: a comparative review. Seminars in Liver Disease 15: 156-164.

20. Konkle BA (2011) Acquired disorders of platelet function. Hematology Am sochematoleduc Program 2011: 391-396.

21. Kotake CK (2000) Practical Pharmacognosy.vallabhprakashan 4: 107-111.

22. Mosmann TR, Coffman RL (1989) Th1 and Th2 cells: Different patterns of lymphokines secretion lead to different functional properties. Annual Review of Immunology 7: 145-173.

23. Ohlsson A, SM Aher (2009) Early erythropoietin for preventing red blood cell transfusion in preterm and low birth weight infants. Journal of Dietary Supplements 6: 227-251.

24. Oyedeji KO, Bolarinwa AF (2013) Effect of Corchorusolitorius Extract on hematological and Plasma Biochemical Parameters in Male Albino Rats. IOSR Journal of Dental and Medical Sciences (IOSR-JDMS) 5: 68-71.

25. Paul H (2005) Platelet function analysis. Blood Reviews 19: 111-123.

26. Ren WZ, Qiao H, Wang L, Zhu L, Zhang (2003) Flavonoids: promising anticancer agents. Medical Research Reviews 23: 519-534

27. Sumit D, Ripunjoy B, Nishant N (2014) A review on the immune modulatory effect of some traditional medicinal herbs. Journal of Pharmaceutical, Chemical and Biological Sciences 2: 33-42. 